\title{
Labor Productivity Assessment Using Activity Analysis on Semi High-Rise Building Projects in Pakistan
}

\author{
Noaman Akbar Sheikh, Fahim Ullah*, Bilal Ayub, and Muhammad Jamaluddin Thaheem \\ Department of Construction Engineering \& Management (CE\&M), NIT-SCEE, National University of \\ Sciences \& Technology (NUST), Islamabad, 44000, Pakistan \\ *Email: fahimullah@nit.nust.edu.pk (Corresponding author)
}

\begin{abstract}
Construction organizations strive to increase their competitiveness by reducing the project costs especially labor cost. Optimizing labor productivity will ensure value for money. In the face of no guidelines available for local construction industry, research must be directed to benchmark construction labor productivity in building projects of Pakistan. Based on a thorough review of established productivity assessment methods, Activity Analysis is performed on five local semi high-rise building projects. Statistical analysis is carried out to identify labor productivity trends in seven standard areas. Further, sensitivity analysis is carried out to characterize the positive and negative influencers. It is revealed that labor spends a little more than one-third of working time in direct and support activities each, and one-quarter in delay activities. Furthermore, delay and support activities are correlated with direct work. Direct work is observed at its peak during midday hours, and lowest during the start and end of workday. The study is an original effort in benchmarking the labor productivity in construction projects of Pakistan. Based on the findings, productivity improvement strategies are proposed from which projects can benefit in the form of optimized costs and schedules. Results are of relevance towards understanding the labor productivity in developing countries.
\end{abstract}

Keywords: Activity analysis, labor productivity, benchmarking, building projects.

ENGINEERING JOURNAL Volume 21 Issue 4

Received 2 November 2016

Accepted 31 January 2017

Published 31 July 2017

Online at http://www.engj.org/

DOI:10.4186/ej.2017.21.4.273 


\section{Introduction}

Competition in construction industry is increasing globally. In such a resource-constrained and profitoriented competitive environment, the costs are optimally decreased in order to increase the market competitiveness. Therefore, it is a common objective of all the construction companies to offer better value against minimum cost [1,2]. On-site labor costs are among the most profit-influencing factors [3]. To reduce them, it is important to improve the labor productivity by identifying and addressing the areas of high and low productivity [4]. This will not only offer strategic advantages to the construction firms, and add to the overall performance management and monitoring but will also highlight the potential areas of improvement to achieve overall organizational goals resulting into optimized cost and better resource management.

According to Rowlinson and Procter [5], labor productivity is the average direct labor hours required to install a unit of material. Hannula [6] describes it as the ratio of total output to total input. Low productivity is a point of concern for construction organizations due to its adverse effects on overall project success in terms of time and cost performance [7]. The significance of controlling labor cost is built into its overall contribution to the project cost. It normally ranges between $33 \%$ to $50 \%$ of total project cost [8]. Having such a significant financial influence, the management of labor productivity becomes even more critical. Thus, it is important to get optimum productivity in order to maximize the profit. To make matters even more challenging, the measurement of labor productivity is another critical issue faced by the industry. In the management literature, it is established that what cannot be measured, cannot be managed [9]. This further stresses the point of having a concrete measurement system for assessing labor productivity. But there is no standard method for measuring labor productivity in the construction industry mainly due to the involvement of complex operations and relationships [10]. The non-availability of reliable data increases the degree of complexity. Furthermore, the challenges of effectiveness of project and quality management, and the technological innovations add to its stochasticity [11].

Labor productivity is a dynamic entity, affected by many elements, and associated with performance of time, cost and quality $[12,13]$. Owing to its substantial impact on overall project success, there is a strong need to assess the performance of labor in order to address the productivity issues. Due to nonstandardization of assessment methods, this performance may be measured and reported in several ways such as calculation of direct productivity unit rates, percent rework and activity levels [11]. Technology has also played its role in facilitating the project managers in productivity assessment [14]. Recently, the use of artificial intelligence is getting popularity in labor productivity measurement [15]. It is intuitive that each method measures the work in separate ways and serves as a good metric for understanding actual labor performance.

Activity Analysis, a refined form of work sampling and activity levels, is another useful method developed by Construction Industry Institute (CII). It includes significantly more detailed observations that are typically broken down into seven standard categories: direct work, preparatory work and instructions, tools and equipment, material handling, waiting, traveling, and personal activities [16]. For maximum productivity, it is important that labors spend more time in doing the direct work such as installing materials. Similarly, some indirect activities like planning, travelling, waiting and personal also impact the overall productivity [11]. So it is necessary to give due considerations to all time consuming direct and indirect activities. This may lead to better understanding of real work percentages, quantification of changes and implementing improvements to increase the direct work [17].

Pakistan, being a developing country, is facing serious issues regarding project management in terms of its success and effective implementation in general, and cost and time overruns in particular [18]. The major reasons for underperformance of local industry are law and order situation, design changes, lack of funds, untrained labor, inexperienced workforce and inadequate management tools and techniques [19-22]. The local inclination towards traditional management practices makes it less innovative, change resistant and extensively labor dependent. Thus, optimum utilization of labor becomes a necessity for achieving the project and corporate goals. Therefore, to address these critical issues, labor productivity assessment and associated management practices need to be explored and responded accordingly. The lack of previous research on this core management area calls for localized assessment of construction projects in terms of their labor productivity.

This research focuses on the assessment and benchmarking of labor productivity by monitoring crew time utilization during working hours for construction projects in Pakistan. For this purpose, the labor productivity of different semi high-rise building construction projects is assessed using Activity Analysis. 
Further the data is quantified using the time expended by labor on productive and non-productive activities. Finally, sensitivity analysis is performed in order to establish a relation between different activity parameters.

\section{Literature Review}

Productivity assessment in the construction industry has been a challenging task since long owing to the involvement of a large number of stochastic variables such as labor intensive work, unique character and uncertainties [23, 24]. This has given rise to diverse definitions of the term. According to Bernolak [25], productivity means "how much and how good we produce from the resources used". Enshassi et al. [26] defines productivity as "how one entity uses its resources to produce outputs from inputs". These definitions generally refer to productivity as a comparison of input and output [27]. Inputs are usually measured in dollars, labor-hours, material, tools and equipment usage whereas outputs are deliverables that contribute to project completion in units of cubic meters of concrete placed, tons of steel erected, length of pipe welded, etc.

Since the labor is acknowledged as the most important factor of production as it creates value and sets the general level of production, labor productivity has been identified as an index for measuring work efficiency [28]. The cost of equipment and material are usually ignored as they are prone to lesser variation in short term projects but the labor productivity varies considerably adding to managerial concerns [26]. Traditionally, labor productivity is interpreted using labor hours and physical output as shown in Eq. (1) [29].

$$
\text { Labor Productivity }=\frac{\text { Labour hours }}{\text { Unit of physical output }}
$$

Due to availability of large amount of productivity assessment techniques, their standardization has raised concern for the practitioners [30]. It can be argued that lack of standardization should not necessarily hamper successful management of labor productivity. However, it surely adds into the managerial decision making while selecting the most optimum technique keeping in view the project constraints and organizational capacity [31]. The pertinent proposed techniques of labor productivity measurement broadly fall under two spectrums: continuous and intermittent, which are observed at three distinct levels of task, project and industry [32]. Thomas and Završki [33] developed a theoretical model for the assessment of construction labor productivity which was criticized due to lack of objectivity [34]. In order to answer this limitation, researchers have stressed the importance of standardized productivity data, if not the technique [35].

Improving productivity is a major concern for any profit-oriented organization, as it provides effective and efficient conversion of resources into marketable products, and determines business profitability [36, 37]. Owing to the lack of standardized productivity data in construction industry, management and desired improvements become a tough ask. In a typical construction project, two primary purposes of measuring productivity are to control cost and schedule, and to obtain data for planning the future projects $[38,39]$. There are several metrics that describe productivity, the most used ones according to Gouett et al. [4] are factor productivity or unit rate (the ratio of labor, material and equipment costs to units of output); labor productivity (the ratio of work hours to units of output); and productivity factor (the ratio of schedule to actual work hours).

These metrics have been criticized because they are often calculated after substantial amount of time at receiving reports from work site [40]. When productivity is measured in this way, areas of low productivity are identified at a later stage and usually substantial damage has been done by then [4]. Though workface assessment techniques, like foreman-delay surveys and craftsman questionnaires, have been developed in an attempt to identify productivity issues immediately, neither of them quantifies all activity levels of a craft worker [41]. Another technique, called continuous observation, quantifies all activity levels but is seldom used due to the discomfort caused to craft workers.

In response to this concern, work sampling was applied in the construction industry to identify problem areas in a timely manner than the productivity metrics [42]. In this context, Choy and Ruwanpura [43], McDonald and Zack [44] and McTague et al. [45] conducted the work sampling analyses, reiterated the findings and revealed that the composition of productive tool time on a construction site generally falls between $40 \%$ and $60 \%$ of the total work time. The studies also unearthed the individual activities that a worker spends his time on and concluded that a considerable amount of time is spent mostly on 
nonproductive activities, such as searching for material, idling and waiting for instructions. As a result, the construction and project management industries have already begun to experience an era of intensified research and development to handle the risks associated with construction [11, 22, 46, 47].

Though work sampling is broadly accepted by experienced managers as an early indicator of productivity issues, it is not a perfect metric. For example, tool time spent on rework is not productive. The method itself is not broadly implemented by industry, because of lack of standard guideline on how to perform it and statistical validation of its effectiveness. Further, work sampling identifies productivity issues, but does not determine the root causes or provide improvement strategies [4]. To address this criticism, Activity Analysis was proposed as a constant improvement process to streamline productivity measurement. It offers a convincing solution for monitoring on-site operations and supports root cause analysis on the issues that adversely affect the productivity. Activity Analysis is defined as "a continuous process of measuring and improving the amount of time that craft workers spend on actual construction... referred as tool time, wrench time, or direct work time" [16]. It extends the work sampling technique into a continuous improvement process, and includes two parts: (1) workface assessment and (2) continuous improvement process. The workface assessment portion of Activity Analysis is the application of work sampling [48]. One of the primary differences between Activity Analysis and work sampling is that it includes significantly more detailed observations and results.

Activity Analysis consists of five steps. Firstly, the study is planned which entails defining the objectives and scope, as well as determining other pertinent details. Secondly, activity sampling is done in order to collect a representative data sample. Each discrete data sample or observation is categorized as direct work, preparatory work, tools and equipment, material handling, waiting, travel, or personal. Thirdly, collected data is analyzed and observations are tabulated to determine activity percentages. The resulting percentages are assessed to determine which types of activities are beyond the acceptable range. Fourthly, potential causes of unacceptable variances are identified and several potential solutions to improve productivity are considered. These improvements are based on a set of factors that include feasibility, logistics and costs. Lastly, the improvements selected in the planning stage are implemented to increase the direct work rate [16].

Pakistan's construction industry is not fully developed and is facing problems like overruns in form of time and cost usually leading to project failures [18]. The in-depth analysis of these delays accentuated labor productivity as a key factor. In addition, poor salary, poor execution and planning, and inefficient equipment are highlighted as key factors contributing to lower labor productivity in road projects in Pakistan [49]. Building projects on the other hand are yet to be explored for labor productivity. Hence the current study targets this useful area of potential value addition to body of knowledge in local context. For this purpose, it makes use of the well-established technique of workface assessment in general and Activity Analysis in particular.

Further, the current study uses the concepts of sensitivity analysis for establishing the correlation between the work activities in accordance with Activity Analysis. Sensitivity analysis is a technique that is used to determine the behavior of a particular dependent variable in response to different values of an independent variable under a given set of assumptions within specified boundaries [50]. It has recently been used by Ökmen and Öztaş [51] in their study of risk based cost model.

\section{Methodology}

The current study revolves around the Activity Analysis for labor productivity computation in the context of Pakistan construction industry. For this purpose, five semi high-rise building construction projects have been explored for work activities by detailed data collection and analysis. The causes of low labor productivity areas are identified to assist mangers in planning and executing improvements. The overall activity rates of workers and the distribution of activity rates throughout a typical workday are determined and improvements are suggested.

Owing to its technical and procedural maturity, Activity Analysis has been selected as a prime candidate technique for this study. Following the methodology given by Gouett et al. [4], various building activities were investigated. The standard questionnaires proposed in aforementioned study were modified for data collection. In order to attain reliable data, the authors personally recorded on-site observations.

The case study projects were selected based on the available resources, ease of access and suitability. Fulfilling these criteria, data is collected from five under construction projects which are located mainly in the federal (northern) region of Pakistan. All these projects are commercial semi high-rise buildings of 
similar nature and were more than $50 \%$ constructed during the data collection phase. Major ongoing activities observed in all these projects were block masonry, plastering, formwork, steel fixing and concrete pouring. Hence the Activity Analysis was mainly observed during these tasks regardless of the number of labor. The number of labors is however recorded and is aimed at conveying the quanta of work being performed. The least limit for number of labors was set at 400, thus all the reported projects have more labors than the set limit. Further, the observations were recorded on modified Gouett et al. [4] form as shown in Fig. 1.

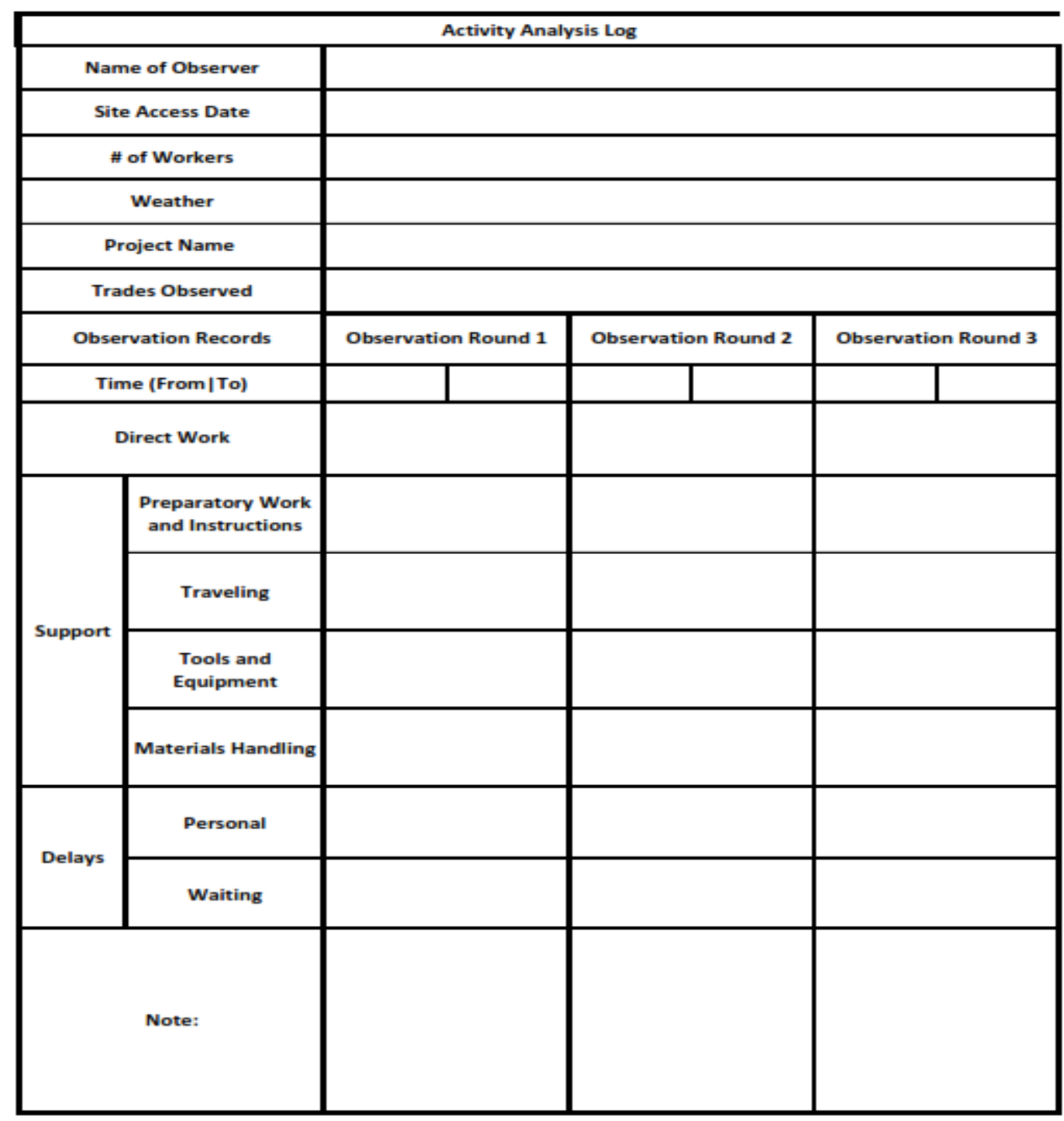

Fig. 1. Hourly activity analysis log.

From Fig. 1, it can be noted that three rounds of observations were recorded for each project on hourly basis for more than 5 days. The authors randomly noted labors at different paths on site for each round by observing them, recording their activities into the standard mentioned categories and denoted it by a tally mark in the corresponding portion. Thus 3 rounds were repeated for each hour and the number of ticks at the end of the hours were recorded to display the number of labors corresponding to each category. The same exercise was repeated for all the hours of observations for more than 5 days and eventually summed up to reveal the total observations in accordance with the standard Activity Analysis procedure. Thus a handsome number of readings is documented and discussed in the result section. 
Table 1. Project description.

\begin{tabular}{llll}
\hline Project & Project Type & Number of Labors & Completion \\
\hline A & Office building & 821 & $76 \%$ \\
B & Commercial apartments & 706 & $52 \%$ \\
C & Hotel building & 495 & $66 \%$ \\
D & Private training institute & 419 & $73 \%$ \\
E & Private healthcare facility & 616 & $59 \%$ \\
\hline
\end{tabular}

Further, according to Gouett et al. [4] the task type does not matter as the observation is restricted to the mentioned categories which are generalized and are common in all types of activities. Thus the focus is not on what the person is doing but rather on the specific category he is falling in at any instant of observation. However, as previously mentioned, the observations were restricted to the established types of block masonry, plastering, formwork, steel fixing and concrete pouring on all the projects. Thus the recorded observations are for the mentioned task types in light of the standard categories. The details of the selected projects are as shown in Table 1. In order to respect the secrecy of the stakeholders and their confidentiality requirements, some of the project information, details of operation and data has been expurgated.

A comprehensive data collection has been performed to understand the pattern of workers spending their time during work day. Other information that can be physically observed at each project site was recorded to aid the data analysis and corresponding results. These observations include important information affecting the productivity on each project like working environment, types of craft mostly employed, weather conditions, labor skills and expertise, safety conditions, construction stage, ongoing activities, etc.

In next stage, keeping in view the desired statistical accuracy, the corresponding sample size, length of the study and workday, and the observation windows were determined. During observations, data was recorded for complete 8 working hours a day for more than 5 consecutive days. Detailed hourly observations at each construction site were ensured in order to increase data reliability. Determining an adequate sample size is critical to the significance of data collection for research [52]. As more samples are collected, the results become more accurate due to reduction of sampling error. However, there is a balance between statistical accuracy and the cost/effort to collect samples. In most industries an error of $\pm 5 \%$ at a confidence level of $95 \%$ is generally acceptable [29].

$$
\mathrm{n}_{0}=\max \frac{\left(\mathrm{z}_{\left(1-\frac{\alpha}{2 \mathrm{~m}}\right)}\right)^{2} \frac{1}{\mathrm{~m}}\left(1-\frac{1}{\mathrm{~m}}\right)}{\mathrm{d}^{2}}
$$

Instead of binomial, Activity Analysis is a multinomial approach because the characteristic being sampled is not the worker, but his behavior at any given time. Thus, multinomial distribution developed by Thompson [53] is used for determining the sample size as shown in Eq. (2). For a given confidence level, it is calculated at varying numbers of categories ' $\mathrm{m}$ ' to find the maximum number of observations ' $\mathrm{n}$ ' in the worst case scenario.

Table 2. Hourly project observations.

\begin{tabular}{|c|c|c|c|c|c|}
\hline \multirow{2}{*}{ Work Hour } & \multicolumn{5}{|c|}{ Number of Observations } \\
\hline & Project A & Project B & Project C & Project D & Project E \\
\hline 08:00-09:00 & 1899 & 1483 & 1511 & 1585 & 1280 \\
\hline 09:00-10:00 & 2292 & 1496 & 1217 & 1499 & 1311 \\
\hline 10:00-11:00 & 1928 & 1435 & 1057 & 1189 & 1184 \\
\hline 11:00-12:00 & 1766 & 825 & 1177 & 1037 & 1766 \\
\hline 12:00-01:00 & 1798 & 972 & 1241 & 1295 & 1190 \\
\hline Lunch & - & - & - & - & - \\
\hline 02:00-03:00 & 2216 & 1451 & 1501 & 1376 & 1332 \\
\hline 03:00-04:00 & 1700 & 1401 & 1107 & 984 & 1076 \\
\hline 04:00-05:00 & 1265 & 1189 & 1179 & 1290 & 1029 \\
\hline Total & 14864 & 10252 & 9990 & 10255 & 10168 \\
\hline
\end{tabular}


For a 95\% confidence level and error of $d=0.05$, the result is $m=3$ and $n=510$ observations. This means that regardless of the number of labor, a total of 510 observations per study period are required to obtain a confidence greater than $95 \%$. Typically, it is desirable to track activity levels for each 1-hour period in the workday, so an 8-hour workday will have 8 study periods, and the study would require a total of 4,080 observations. In accordance with these requirements, Table 2 summarizes the number of samples collected for every observation per hour of each project.

\section{Results and Discussions}

After data collection, the observations were divided into the previously mentioned seven categories as shown in Table 3.

As evident from the observations, Project A has a very high direct work percentage due to the fact that in this project, in contrast to others, overall work activities were properly planned and supervised by competent professionals with high level of coordination with labors. It has already been established that better planning positively influences the productive work [54]. It is to be mentioned that tools and equipment, and material handling activities are much lower as compared to other counterparts paving the way for increased direct work time. Further, at this project, there were proper plans for both tools and materials in terms of availability, maintenance and monitoring. Similarly, materials were properly handled and placed near the working areas, reducing the unnecessary travel time. The safety of workers was also ensured, imparting the feeling of comfort to them leading to increase in direct work rate.

Table 3. Work activity percentages.

\begin{tabular}{|c|c|c|c|c|c|c|c|}
\hline \multicolumn{2}{|c|}{ Activities } & $\begin{array}{l}\text { Project A } \\
(\%)\end{array}$ & $\begin{array}{l}\text { Project B } \\
(\%)\end{array}$ & $\begin{array}{l}\text { Project } \\
\text { C (\%) }\end{array}$ & $\begin{array}{l}\text { Project } \\
\text { D (\%) }\end{array}$ & $\begin{array}{l}\text { Project } \\
\text { E (\%) }\end{array}$ & $\begin{array}{l}\text { Average } \\
(\%)\end{array}$ \\
\hline \multicolumn{2}{|c|}{ Direct Work } & 41.1 & 37.9 & 29.0 & 33.2 & 31.0 & 34.4 \\
\hline \multirow{5}{*}{ Support } & Preparatory & & & & & & \\
\hline & $\begin{array}{l}\text { Work and } \\
\text { Instructions }\end{array}$ & 9.2 & 8.8 & 8.1 & 9.3 & 10.2 & 9.1 \\
\hline & Traveling & 12.6 & 11.9 & 13.6 & 12.0 & 15.3 & 13.1 \\
\hline & $\begin{array}{ll}\text { Tools } & \text { and } \\
\text { Equipment }\end{array}$ & 3.7 & 6.4 & 9.2 & 8.7 & 8.7 & 7.4 \\
\hline & $\begin{array}{l}\text { Materials } \\
\text { Handling }\end{array}$ & 4.3 & 5.9 & 11.5 & 9.1 & 11.6 & 8.5 \\
\hline \multirow{2}{*}{ Delays } & Personal & 17.7 & 18.4 & 17.6 & 17.0 & 14.3 & 17.0 \\
\hline & Waiting & 11.2 & 10.7 & 11.0 & 10.6 & 8.8 & 10.5 \\
\hline
\end{tabular}

In comparison, Project $\mathrm{C}$ experienced the lowest direct work rate because of more indirect activities, reducing the time cushion for direct work. Primary cause was the financial crisis in project due to which a large number of supervising staff was dismissed. Work was not effectively supervised resulting into wastage of time by labor in indirect activities.

Comparison of case studies with Project E reveals very high percentages of preparatory work and instructions, and travelling. This was mainly due to inexperienced labor, poorly organized project site and minimal coordination between site staff and labor. One of the primary causes was that majority of labors were hired from subcontractors who were inexperienced and site staff was not properly coordinating with them. Other reasons include the longer distance from working areas to site office. Further, necessary facilities like drinking water, toilet, etc., were not provided at working area leading to increased travelling.

To increase the direct work activity, all other activities should be minimized as witnessed in these case studies. Project A has highest direct work rate due to low value of other activities. Similarly, Project C experienced low direct work due to greater indirect activities. Hourly direct work for all the projects is reported in Table 4 providing insights into the direct work distribution per hour and can be used to highlight the hours of maximum and minimum productivity. 
Table 4. Hourly direct work activity rates.

\begin{tabular}{llllllllll}
\hline $\begin{array}{l}\text { Percent } \\
\text { Hourly } \\
\text { Work }\end{array}$ & $\begin{array}{l}\mathbf{8 a m}- \\
\text { 9am }\end{array}$ & $\begin{array}{l}\text { 9am- } \\
\text { 10am }\end{array}$ & $\begin{array}{l}\text { 10am- } \\
\text { 11am }\end{array}$ & $\begin{array}{l}\text { 11am- } \\
\text { 12pm }\end{array}$ & $\begin{array}{l}\text { 12pm- } \\
\text { 1pm }\end{array}$ & $\begin{array}{l}\text { 1pm- } \\
\text { 2pm }\end{array}$ & $\begin{array}{l}\text { 2pm- } \\
\text { 3pm }\end{array}$ & $\begin{array}{l}\text { 3pm- } \\
\text { 4pm }\end{array}$ & $\begin{array}{l}\text { 4pm- } \\
\text { 5pm }\end{array}$ \\
\hline Project A & 35.07 & 42.71 & 43.10 & 44.85 & 42.27 & - & 39.40 & 37.88 & 44.82 \\
Project B & 23.74 & 40.71 & 43.34 & 41.58 & 40.12 & - & 33.29 & 42.97 & 40.45 \\
Project C & 25.35 & 28.10 & 31.32 & 34.83 & 28.28 & - & 27.38 & 30.26 & 28.24 \\
Project D & 27.82 & 30.75 & 36.50 & 41.85 & 31.66 & - & 31.10 & 40.55 & 30.78 \\
Project E & 22.19 & 30.28 & 33.61 & 36.06 & 31.51 & - & 27.03 & 37.83 & 32.36 \\
\hline
\end{tabular}

As evident from Table 4, in all projects, the direct work is lowest at the start of the day. It then increases over time until midday $(11 \mathrm{am}-12 \mathrm{pm})$ where it peaks and finally starts decreasing towards lunch break. After lunch, it again starts increasing until the second last hour and eventually starts decreasing in the last hour. Peak direct work rate is recorded during $11 \mathrm{am}-12 \mathrm{pm}$ hour and lowest direct rate is observed during 8am-9am. It should be noted that direct work activity is at maximum at the second last hour both before and after lunch as shown in Fig. 2. It must be noted that the values presented in corresponding tables are not plain averages but are weighted averages taking into account the difference of observations for different projects at various time slots. For example, in Table 3, the value of direct work for Project A is 41.1 as weighted average which if taken as plain average of the values in Table 4 comes out to be 41.3. This is done to incorporate the due share of different observations for various projects and time slots.

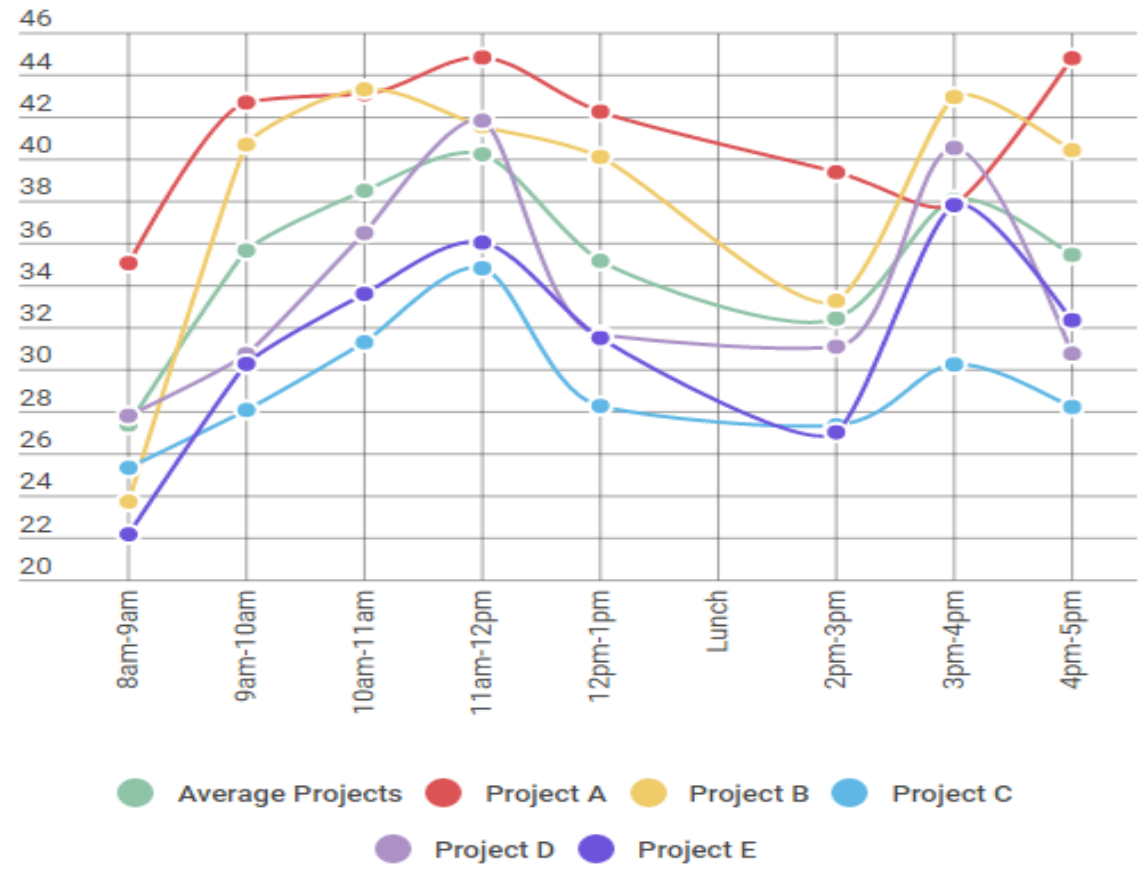

Fig 2. Hourly trend of direct work rates.

It was recorded during the observations that generally people start their work late as depicted by the lower productivity in graph for first hour. Then an increasing trend is observed pointing to more direct work with passing time until the last hour before lunch. This depression in the graph points to the fact that people often start leaving the workplace for lunch 10-15 minutes before due time. Same trend is generally observed after lunch. Exclusive to Project A, there was a scheduled tea break of 15-20 minutes between 3-4 $\mathrm{pm}$ hence it depicts low direct work during this time. But this project shows an increasing trend in the last hour due to routine checks of everyday work at the closing time pushing the labors to complete their remaining work. 
Table 5. Hourly distribution of observation for activities.

\begin{tabular}{|c|c|c|c|c|c|c|c|c|c|c|c|}
\hline \multicolumn{2}{|c|}{ Time } & 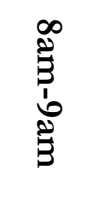 & 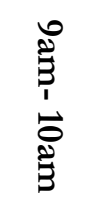 & 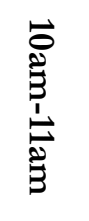 & 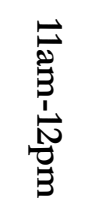 & 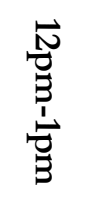 & \begin{tabular}{l}
$\overrightarrow{5}$ \\
\multirow{2}{*}{} \\
\multirow{3}{*}{}
\end{tabular} & 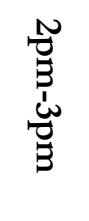 & 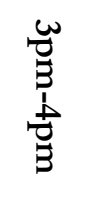 & $\begin{array}{l}\vec{t} \\
\vec{J} \\
\dot{j} \\
\vec{b}\end{array}$ & 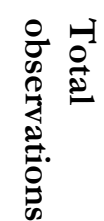 \\
\hline \multicolumn{2}{|c|}{ Direct Work } & 2126 & 2788 & 2616 & 2371 & 2286 & \multirow{7}{*}{ Lunch } & 2555 & 2387 & 2111 & 19240 \\
\hline \multirow{4}{*}{$\begin{array}{l}\mathscr{E} \\
\frac{E}{8} \\
\frac{8}{7}\end{array}$} & $\begin{array}{l}\text { Preparatory Work } \\
\text { and Instructions }\end{array}$ & 1070 & 822 & 581 & 432 & 470 & & 723 & 495 & 406 & 4999 \\
\hline & Traveling & 1134 & 936 & 746 & 611 & 1161 & & 1146 & 563 & 851 & 7148 \\
\hline & $\begin{array}{l}\text { Tools } \\
\text { Equipment }\end{array}$ & 694 & 524 & 454 & 378 & 412 & & 553 & 398 & 442 & 3855 \\
\hline & Materials Handling & 678 & 649 & 503 & 546 & 513 & & 595 & 510 & 436 & 4430 \\
\hline \multirow{2}{*}{ 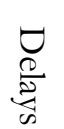 } & Personal & 1159 & 1286 & 1224 & 1006 & 1039 & & 1402 & 1196 & 1072 & 9384 \\
\hline & Waiting & 897 & 810 & 669 & 548 & 615 & & 902 & 719 & 634 & 5794 \\
\hline \multicolumn{2}{|c|}{ Total } & 7758 & 7815 & 6793 & 5892 & 6496 & & 7876 & 6268 & 5952 & 54850 \\
\hline
\end{tabular}

In order to generalize the results and benchmark the labor productivity, results of all the observations on five construction projects are shown in Table 5. Each number represents the characteristics of labor's working behavior as observed and categorized into seven activities, further summed into three main classes: direct, support and delay in accordance to CII.

Table 6. Percentage of work activities.

\begin{tabular}{|c|c|c|c|}
\hline \multicolumn{2}{|l|}{ Activities } & \multicolumn{2}{|c|}{ Percentages } \\
\hline Direct Work & & \multicolumn{2}{|l|}{35.08} \\
\hline \multirow{4}{*}{ Support } & Preparatory Work and Instructions & \multirow{4}{*}{37.25} & 9.11 \\
\hline & Traveling & & 13.03 \\
\hline & Tools and Equipment & & 7.03 \\
\hline & Materials Handling & & 8.08 \\
\hline \multirow{2}{*}{ Delays } & Personal & \multirow{2}{*}{27.67} & 17.11 \\
\hline & Waiting & & 10.56 \\
\hline
\end{tabular}

As presented in Table 6, support activities share large percentage following direct work and delay activity with values $37.25 \%, 35.08 \%$ and $27.67 \%$ respectively. Primary activities were analyzed in details by exploring their secondary activities in which comprehensive investigation of recorded data was done and all the percentages of secondary activities were calculated accordingly. As per Table 6, in support category, travelling shares the larger portion whereas in delay category, personal activities have the largest share. It can be observed that secondary activities holding larger percentage after direct work are personal, travelling and waiting. So, in order to increase the direct work, these activities should be controlled and streamlined. Further, other dependent activities should also be minimized as their reduction will eventually increase the direct work ultimately leading to increased labor productivity and enhanced project success.

It is intuitive that in order to increase the overall direct work rate, areas of lower productivity throughout the day should be avoided as much as possible. This can be done by proper planning and monitoring of overall work activities. Management should investigate into the fluctuating rate throughout the day and should take necessary action in order to minimize it using the methodology of this study. Further, it is recommended that site management should direct the labor to work in proper hours rather than starting the work late or leaving early from site.

To facilitate the managerial decision making while resolving on-site productivity issues, the tradeoff between direct work and personal time must be clearly understood. In order to find out relation between direct work activities with other activities, sensitivity analysis was performed using @RISK® software with all 54,850 observed data points. Firstly, an equation was derived using regression analysis function of MS 
Excel ${ }^{\circledR}$. Following this equation, regression and correlation coefficients of each activity with direct work were calculated as shown in Table 7.

Table 7. Regression and correlation for direct work with other activities.

\begin{tabular}{llll}
\hline Rank & Name & Regression & Correlation \\
\hline 1 & Personal & 0.589 & 0.585 \\
2 & Waiting & -0.562 & -0.549 \\
3 & Preparatory Work and Instructions & 0.443 & 0.448 \\
4 & Tools and Equipment & -0.339 & -0.343 \\
5 & Materials Handling & 0.133 & 0.115 \\
6 & Traveling & 0.045 & 0.045 \\
\hline
\end{tabular}

From Table 7, it can be observed that personal activity is sensitive to direct work with correlation and regression coefficients of 0.585 and 0.589 respectively. Waiting is the second activity which negatively affects the direct work with a correlation and regression values of 0.562 and 0.549 . Whereas preparatory work and instructions, and tools and equipment activities are ranked third and fourth. Lastly, materials handling and travelling activities are ranked fifth and sixth respectively. It can be argued that a correlation of 0.585 is weak but comparatively it is the most influential among all the activities. The correlation was further analyzed by the application of ANOVA for any statistically significant differences. The p-values for the personal and waiting activities came out to be 0.13 and 0.21 respectively which satisfies $p>0.05$ thus making the difference "not significant". The p-values for all the categories, as shown in Table 8 , follow the same pattern and can be marked to have no significant difference thus statistically validate for considerable correlation.

Table 8. P- values of Activities.

\begin{tabular}{lll}
\hline Rank & Name & P-Values \\
\hline 1 & Personal & 0.13 \\
2 & Waiting & 0.21 \\
3 & Preparatory Work and Instructions & 0.40 \\
4 & Tools and Equipment & 0.58 \\
5 & Materials Handling & 0.45 \\
6 & Traveling & 0.56 \\
\hline
\end{tabular}

Personal, and preparatory work and instructions positively affect the direct work activity while waiting, and tools and equipment inversely affect it. From Table 7, it can be inferred that when the workers are comfortable in doing their work, they will exert more efforts in their activities, enhancing the project [55]. It was observed that labors feel uncomfortable when project staff overly controls or restricts their personal activities (gossiping and having tea or smoke break). To this extent, after spending some time in personal activities, they concentrate effectively on direct activities. On the other hand, if their mind is preoccupied with unfriendly restrictions, they find it hard to concentrate effectively on their tasks. It is a commonly perceived notion in local projects that subcontracted labors who work on their own schedules with more liberty to set their work plans perform better. Not only they complete tasks in optimum time, a cost reduction is also realized due to reduced supervision expenses.

Instead of restricting personal activities, management should focus on areas of pilferage activities: late starts at beginning of work day, around lunch and early quits at the end of the day. Better planning and onsite supervision during these times should limit the number of craft purposely starting slowly, or waiting to clock-out. Also, increased sense of job satisfaction will positively drive the workers towards enhanced productivity.

Similarly, it is analyzed that with increased time in preparatory work and instructions, more direct work is carried out. Many times during construction, labors are unable to determine the job requirements usually due to lack of necessary instruction to perform the work. So, if more time is allocated to preparatory work, the increased understanding of job requirements and proper execution methods will ensure timely completion [7]. Further, the unnecessary tasks should be eliminated, while the essential activities may still be 
excessive depending upon their job related criticality. These include ergonomics, safety talks and stretching activities as they are crucial for maintaining a well-functioning and safe construction site [56].

Talking about the negative relation, it is concluded that with more time in waiting, and tools and equipment activities, lesser direct work is achieved. When the labor is involved in waiting, though the time is essentially spent on project activities, the result is not so effective mainly due to poor activity planning. Due to this lack of planning, they are not actually performing the work but are waiting for someone to finish their job resulting in delayed work and queuing. In some instances, the waiting is unavoidable, like electricians waiting for a cable pull. Usually it is caused by poor planning and crew balance, and is therefore avoidable [57]. To improve the productivity, site management team should properly plan the work in order to minimize the labor waiting or use innovative and latest techniques like lean management $[58,59]$.

Tools and equipment also follow a negative relation with direct work. It is observed that with more labor effort on tools and equipment activities, direct work will be reduced [60]. It is usually caused due to poor tool management at project site. So, it is suggested that site management should properly implement tool management program and ensure timely availability of tools and equipment. Furthermore, the results of assessment performed in the current study were shared with the field professionals working on the case study project to validate the observations. This fortifies the results of current study which, apart from benchmarking the labor productivity, identify holistic reasons for productivity loss on the case study projects.

\section{Conclusions and Recommendations}

Construction companies increase their profit and market competitiveness by controlling their costs. These include labor, material and overhead costs, of which labor varies the most. This ultimately sums into the variable labor productivity which must be kept in check to ensure project success. This research is mainly focused on assessment of labor productivity in semi high-rise commercial building projects in Pakistan based on the crew time utilization during working hours.

To measure the direct and indirect work time, the most relevant technique identified in literature, Activity Analysis, is used in the current study. Hence detailed analysis is carried out at five building projects. The activity rates of labors and their distribution over a typical workday are determined. The rates are analyzed to identify productivity factors which should be managed in order to improve the direct work rate. Further, sensitivity analysis is carried out to highlight the interdependencies of work activities. The case studies reveal that labor should be spending more time doing the direct work for maximum productivity.

Owing to the findings of sensitivity analysis, it is concluded that direct work is moderately correlated to delay and support work activities. But in the support activity, material handling and travelling are weakly correlated to direct work. It is established that personal and preparatory works positively influence the overall direct work, and waiting, and tools and equipment negatively influence it. Hence in order to maximize labor productivity, direct as well as support work activities should be efficiently managed. Further, planning, coordination and supervision are essential for increasing the effectiveness of employees and maintaining the required daily output level. Case studies reveal that the projects with better planning, monitoring and control, inarguably perform better in terms of direct work. Improving the productivity of entire project is not possible until everyone is committed to continuous improvement.

Analyzing the hourly direct work rate on all projects, it is found that this rate peaks during $11 \mathrm{am}$ to $12 \mathrm{pm}$ slot, and is minimum during the start and end of working day. Also, generally about $35 \%$ of working time is utilized in direct work, $37 \%$ in support work and $28 \%$ in delay work activities. Specifically, in terms of individual activities, about $17 \%$ time is utilized in personal activities which is the $2^{\text {nd }}$ highest proportion after direct work. Hence, the personal time must be properly managed in conjunction with direct work in order to ensure project success and achieve maximum productivity. Also to increase the direct work, it is recommended to hire experienced craft workers or provide proper trainings, plan good site layout, ensure availability of all required materials and tools, maintain site management presence, and plan the work task for timely execution. This will ensure maximum productivity in terms of more direct work and reduced undesired work.

The current research sets the baseline for construction labor productivity assessment in Pakistan. Owing to the lack of previous research on local labor productivity, it is an advancement in the currently localized body of knowledge and has high research implication for local institutions. The results have been shared with the local field professionals, who validated the identified reasons of low productivity. This 
study can be generalized for countries of similar characteristics and will be a useful addition to the local construction management community.

For future research, labor productivity should be continuously monitored throughout the life of a construction project for more in-depth analysis. The current study uses the workface assessment technique which can be further enhanced in future by not only increasing the number of projects but also using it in conjunction with other monitoring techniques to add value to the existing body of knowledge.

\section{References}

[1] B. Ayub, M. J. Thaheem, and Z. ud Din, "Dynamic management of cost contingency: Impact of KPIs and risk perception," Procedia Engineering, vol. 145, no. 1, pp. 82-87, 2016.

[2] Z. Shehu, I. R. Endut, A. Akintoye, and G. D. Holt, "Cost overrun in the Malaysian construction industry projects: A deeper insight," International Journal of Project Management, vol. 32, no. 8, pp. 14711480, 2014.

[3] A. S. Hanna, C.-K. Chang, K. T. Sullivan, and J. A. Lackney, "Impact of shift work on labor productivity for labor intensive contractor," Journal of Construction Engineering and Management, vol. 134, no. 3, pp. 197-204, 2008.

[4] M. C. Gouett, C. T. Haas, P. M. Goodrum, and C. H. Caldas, "Activity analysis for direct-work rate improvement in construction," Journal of Construction Engineering and Management, vol. 137, no. 12, pp. 1117-1124, 2011.

[5] M. Rowlinson and S. Procter, "Organizational culture and business history," Organization Studies, vol. 20, no. 3, pp. 369-396, 1999.

[6] M. Hannula, "Total productivity measurement based on partial productivity ratios," International Journal of Production Economics, vol. 78, no. 1, pp. 57-67, 2002.

[7] A. M. Jarkas and C. G. Bitar, "Factors affecting construction labor productivity in Kuwait," Journal of Construction Engineering and Management, vol. 138, no. 7, pp. 811-820, 2011.

[8] G. Jergeas, "Improving construction productivity on Alberta oil and gas capital projects," Alberta Finance and Enterprise, University of Calgary, Alberta, Canada, 2009.

[9] A. de Waal and K. Kourtit, "Performance measurement and management in practice: Advantages, disadvantages and reasons for use," International Journal of Productivity and Performance Management, vol. 62, no. 5, pp. 446-473, 2013.

[10] P. Crawford and B. Vogl, "Measuring productivity in the construction industry," Building Research \& Information, vol. 34, no. 3, pp. 208-219, 2006.

[11] W. Yi and A. P. Chan, "Critical review of labor productivity research in construction journals," Journal of Management in Engineering, vol. 30, no. 2, pp. 214-225, 2013.

[12] S. Mahmood, S. M. Ahmed, K. Panthi, and N. Ishaque Kureshi, "Determining the cost of poor quality and its impact on productivity and profitability," Built Environment Project and Asset Management, vol. 4, no. 3, pp. 296-311, 2014.

[13] T. Maruyama, H. Karasawa, S. Hashimoto, and S. Date, "Effect of expansive agent and temperature on the quality of pre-cast concrete products," International Journal of Civil Engineering, vol. 15, no. 2, pp.263-271, 2017.

[14] W. Jiradamkerng, "Evaluation of EZStrobe simulation system as a tool in productivity analysis-A case study: Precast concrete hollow-core slab installation," Engineering Journal, vol. 17, no. 2, pp. 75-84, 2012.

[15] E. L. Oral, M. Oral, and M. Andaç, "Construction crew productivity prediction: Application of two novel methods," International Journal of Civil Engineering, vol. 14, no. 3, pp. 181-186, 2016.

[16] Construction Industry Institute, Guide to Activity Analysis. Austin, USA: University of Texas, 2010.

[17] R. Fulford and C. Standing, "Construction industry productivity and the potential for collaborative practice," International Journal of Project Management, vol. 32, no. 2, pp. 315-326, 2014.

[18] A. Maqsoom and C. Charoenngam, "Motives and competitive assets of Pakistani international construction contracting firms: Impact of size and international experience," Journal of Financial Management of Property and Construction, vol. 19, no. 2, pp. 138-151, 2014.

[19] R. M. Choudhry, M. A. Aslam, J. W. Hinze, and F. M. Arain, "Cost and schedule risk analysis of bridge construction in Pakistan: Establishing risk guidelines," Journal of Construction Engineering and Management, vol. 140, no. 7, pp. 04014020, 2014. 
[20] R. U. Farooqui and S. Azhar, "Key causes of disputes in the Pakistani construction industryassessment of trends from the viewpoint of contractors," in 50th Annual International Conference of the Associated Schools of Construction, Washington, DC, March 2014, pp. 26-28.

[21] S. S. S. Gardezi, I. A. Manarvi, and S. J. S. Gardezi, "Time extension factors in construction industry of Pakistan," Procedia Engineering, vol. 77, pp. 196-204, 2014.

[22] F. Ullah, B. Ayub, S. Q. Siddiqui, and M. J. Thaheem, "A review of public-private partnership: Critical factors of concession period," Journal of Financial Management of Property and Construction, vol. 21, no. 3, pp. 269-300, 2016.

[23] R. H. Abdel-Razek and M. Abdel-Hamid, "Labor productivity: Benchmarking and variability in Egyptian projects," International Journal of Project Management, vol. 25, no. 2, pp. 189-197, 2007.

[24] S. T. Ng, R. M. Skitmore, K. C. Lam, and A. W. Poon, "Demotivating factors influencing the productivity of civil engineering projects," International Journal of Project Management, vol. 22, no. 2, pp. 139-146, 2004.

[25] I. Bernolak, "Effective measurement and successful elements of company productivity: The basis of competitiveness and world prosperity," International Journal of Production Economics, vol. 52, no. 1, pp. 203-213, 1997.

[26] A. EnShassi, S. Mohamed, P. Mayer, and K. Abed, "Benchmarking masonry labor productivity," International Journal of Productivity and Performance Management, vol. 56, no. 4, pp. 358-368, 2007.

[27] S. Tangen, "Demystifying productivity and performance," International Journal of Productivity and Performance Management, vol. 54, no. 1, pp. 34-46, 2005.

[28] O. Ameh and K. Odusami, "Factors affecting labor productivity in the Nigerian construction industry-A case study of indigenous contracting organization in Lagos," The Quantity Surveyor, vol. 40, no. 3, pp. 14-18, 2002.

[29] M. P. Groover, Work Systems and the Methods, Measurement, and Management of Work. Upper Saddle River, NJ: Pearson Prentice Hall, 2007.

[30] N. A. Karim, S. H. Hassan, J. N. Yunus, and M. Hashim, "Factors influence labour productivity and the impacts on construction industry," Caspian Journal of Applied Sciences Research, vol. 2, pp. 349-354, 2013.

[31] W. Jiradamkerng, "Productivity management of road construction in Thailand by EZStrobe simulation system case study: $0.15 \mathrm{~m}$. thick subbase course construction," Engineering Joumal, vol. 20, no. 3, pp. 183-195, 2016.

[32] I. Noor, "Measuring construction labor productivity by daily visits," AACE International Transactions, p. PR16, 1998.

[33] H. R. Thomas and I. Završki, "Construction baseline productivity: Theory and practice," Journal of Construction Engineering and Management, vol. 125, no. 5, pp. 295-303, 1999.

[34] C.-L. Lin and H.-M. Huang, "Improved baseline productivity analysis technique," Journal of Construction Engineering and Management, vol. 136, no. 3, pp. 367-376, 2009.

[35] W. Briec, K. Kerstens, and N. Peypoch, "Exact relations between four definitions of productivity indices and indicators," Bulletin of Economic Research, vol. 64, no. 2, pp. 265-274, 2012.

[36] S. Wilcox, B. Stringfellow, R. Harris, and B. Martin, "Management and productivity," Transportation Research Board, Committee on Management and Productivity, Washington, USA, 2000.

[37] D. E. Ighravwe and S. A. Oke, "Machining performance analysis in end milling: predicting using ANN and a comparative optimisation study of ANN/BB-BC and ANN/PSO," Engineering Journal, vol. 19, no. 5, pp. 121-137, 2015.

[38] Y. Jung and S. Kang, "Knowledge-based standard progress measurement for integrated cost and schedule performance control," Journal of Construction Engineering and Management, vol. 133, no. 1, pp. 10 21, 2007.

[39] A. Kaveh, M. Khanzadi, and M. Alipour, "Fuzzy resource constraint project scheduling problem using CBO and CSS algorithms," International Journal of Civil Engineering, vol. 14, no. 5, pp. 325-337, 2016.

[40] S. Sarhan and A. Fox, "Barriers to implementing lean construction in the UK construction industry," The Built \& Human Environment Review, vol. 6, no. 1, pp. 1-17, 2013.

[41] A. A. Tsehayae, A. A. Tsehayae, A. R. Fayek, and A. R. Fayek, "System model for analysing construction labour productivity," Construction Innovation, vol. 16, no. 2, pp. 203-228, 2016.

[42] T. Cheng, M. Venugopal, J. Teizer, and P. Vela, "Performance evaluation of ultra wideband technology for construction resource location tracking in harsh environments," Automation in Construction, vol. 20, no. 8, pp. 1173-1184, 2011. 
[43] E. Choy and J. Y. Ruwanpura, "Predicting construction productivity using situation-based simulation models," Canadian Journal of Civil Engineering, vol. 33, no. 12, pp. 1585-1600, 2006.

[44] D. McDonald and J. Zack, "Estimating lost labor productivity in construction claims," in $A A C E$ International Recommended Practice No. 25R, 2004.

[45] B. McTague and G. Jergeas, "Productivity improvements on Alberta major construction projects: Phase I-Back to basics," Alberta Economic Development, 2002.

[46] S. Babar, M. J. Thaheem, and B. Ayub, "Estimated cost at completion: Integrating risk into earned value management," Journal of Construction Engineering and Management, vol. 143, no. 3, p. 04016104, 2016.

[47] F. Nasirzadeh, H. Mazandaranizadeh, and M. Rouhparvar, "Quantitative risk allocation in construction projects using cooperative-bargaining game theory," International Journal of Civil Engineering, vol. 14, no. 3, pp. 161-170, 2016.

[48] A. Khosrowpour, J. C. Niebles, and M. Golparvar-Fard, "Vision-based workface assessment using depth images for activity analysis of interior construction operations," Automation in Construction, vol. 48, pp. 74-87, 2014.

[49] A. B. Muzamil and B. Khurshid, "Analysis of labour productivity of road construction in Pakistan," International Journal of Engineering and Advanced Technology (IJEAT), vol. 3, no. 3, pp. 153-159, 2014.

[50] A. Saltelli, K. Chan, and E. M. Scott, Sensitivity Analysis, vol. 1. New York: Wiley, 2000.

[51] Ö. Ökmen and A. Öztaş, "Scenario based evaluation of a cost risk model through sensitivity analysis," Engineering, Construction and Architectural Management, vol. 22, no. 4, pp. 403-423, 2015.

[52] L.-R. Yang, J.-H. Chen, and H.-W. Wang, "Assessing impacts of information technology on project success through knowledge management practice," Automation in Construction, vol. 22, pp. 182-191, 2012.

[53] S. Thompson, Sampling. New York: John Wiley and Sons, 1992.

[54] P. Ghoddousi, O. Poorafshar, N. Chileshe, and M. R. Hosseini, "Labour productivity in Iranian construction projects: Perceptions of chief executive officers," International Journal of Productivity and Performance Management, vol. 64, no. 6, pp. 811-830, 2015.

[55] P. Böckerman and P. Ilmakunnas, "The job satisfaction-productivity nexus: A study using matched survey and register data," Industrial \& Labor Relations Review, vol. 65, no. 2, pp. 244-262, 2012.

[56] R. M. Choudhry and H. Zahoor, "Strengths and weaknesses of safety practices to improve safety performance in construction projects in Pakistan," Journal of Professional Issues in Engineering Education and Practice, vol. 142, no. 4, p. $04016011,2016$.

[57] N. Vilasini, T. R. Neitzert, and J. Gamage, "Lean methodology to reduce waste in a construction environment," in 15th Pacific Association of Quantity Surveyors Congress, Colombo, Sri Lanka, 2011,

[58] S. Q. Siddiqui, F. Ullah, M. J. Thaheem, and H. F. Gabriel, "Six sigma in construction: A review of critical success factors," International Journal of Lean Six Sigma, vol. 7, no. 2, pp. 171-186, 2016.

[59] L. Song and D. Liang, "Lean construction implementation and its implication on sustainability: A contractor's case study," Canadian Journal of Civil Engineering, vol. 38, no. 3, pp. 350-359, 2011.

[60] P. Ghoddousi and M. R. Hosseini, "A survey of the factors affecting the productivity of construction projects in Iran," Technological and Economic Development of Economy, vol. 18, no. 1, pp. 99-116, 2012. 